\title{
A study of English writing teaching mode based on computer network corpus
}

ZHENG Weiwei ${ }^{1, a}$

\author{
${ }^{1}$ Jilin Business and Technology College, Changchun 130000, China \\ aemail: zhengweiwei@163.com
}

Keywords: Network corpus; BNC; Cobuild; LDC; classroom English Teaching

\begin{abstract}
Network corpus is extremely convenient language learning and research resources. Some of them free and open to the public, the corpus has very high use value, can make use of the network resources to support classroom English teaching is domestic and foreign linguists and language teachers are concerned about in recent years. The real data in an attempt to solve the practical problems of Web corpus in the teaching practice, that some large Web corpus can be used in classroom English teaching.
\end{abstract}

\section{Introduction}

The modern corpus is the true language of electronic text database. Users can search through the program contains all the keywords extraction or structure statement from the corpus, analyzed the structure and comparison of words, language phenomenon. The electronic corpus for language research and teaching to provide a very convenient tool. Particularly important corpus in foreign language teaching, it can help to narrow the gap between the reality and the real language foreign language learning in the classroom. But the current domestic application still remains in a small number of experts and scholars on the research. The corpus has not really entered the English classroom teaching. With the rapid development of the network and the people to understand the use of corpus corpus, foreign language teaching in the development of cyber source has become possible. The direct use of the Web corpus is very convenient resources for language teaching, can make use of these resources, rapid change the backward mode of foreign language teaching, improve the quality of foreign language teaching is a problem for foreign language educators are concerned about in recent years. This paper will use some examples in the teaching practice of Web corpus shows that the network corpus is very useful and can help the English teaching resources[1].

There is a great difference between the scale and the quality of the network in the corpus, by contrast to many years, the author thinks that several can be used directly for the large corpus as the main foreign language teaching resources. British National Corpus (BNC) is the current network can directly use the largest corpus, it by the Oxford University Press and several dictionary publishers and scientific research institutions teamed up to create and completed in 1994, BNC word capacity of more than 100 million. By 4124 represent a wide range of modern British English text, including national and local newspapers, all kinds of periodicals, magazines, books of the theory, popular fiction, college papers, letters and conversations text, $90 \%$ of which are written, $10 \%$ for oral English. COBUILD corpus is the first appeared in the network era of large corpora, the name for English Bank (the Bank of English), the Collins press in collaboration with the University of Birmingham, completed in 1991, after the corpus has continued to expand, to January 2002, the capacity of the English word pool has reached Siyiwu_qianwan million. Can be directly retrieved in the network containing forty-five million word corpus trial (Corpus Concordance Sampler). Cobuild Collins has become the source of the corpus of dictionaries and grammars. LDC is the abbreviation of the Linguistic Data Consortium (The), the University, the company and the government research department established in 1992, the University of Pennsylvania as the seat of the union. The alliance under construction is equivalent to the BNC American National Corpus ANC, in order to adapt to the demand of American Studies at home and abroad ANC will open to the general users in 2007. The LDC in the online publication of the corpus of a few blocks, 
including LDC93T1 Brown corpus and a portion of the eighties of the Wall Street Journal, including part of the 1990s New York Times, Los Angeles Times, the Washington Post, Reuters news LDC95T6. Also includes The Associated Press and other publications of the TIPSTER LDC93T3.

From the content, the three corpora are adequate corpus, wide range of subjects, can reflect a variety of language phenomenon in contemporary english. These corpora are not only a good tool for linguists and dictionary makers, but also a source of endless corpus consultation for teachers, students and translators. The frequency of common phrases and structures in the corpus can directly reflect the size of the corpus and the breadth of the subject matter[2].

\section{Application of Web corpus in English Teaching in classroom}

Retrieved from sampling, BNC directly given in the form of sentence retrieval results, if sample sentences more than 50, again click search health, view more sample sentences. The retrieval results to sentence alignment as to the keywords in the middle (KWIC) way of eye-catching, KWIC a glance gives the feeling, but the sentence can query to provide more context, convenient for the teacher to choose.. In addition, the query can also register to the Sara search procedures, query syntax structure or context information in a variety of ways. COBUILD just BNC, used KWIC provide query results, although cannot expand a sentence really makes people feel the view is limited, but the direct a variety of query and word frequency statistics enable query feel COBUILD networks are still rare in language learning and research tool, in analysis of word collocation and syntactic structure COBUILD observation is more obvious. LDC retrieval both BNC and COBUILD two corpus characteristics can to keywords center display the retrieved results, and will provide a sentence or paragraph, also you can flip to see 100 sentence after sentence. Certainly the development trend of the internet corpus is to convenient query, but also functional, in this regard, the late American National Corpus ANC will be more than BNC and Cobuild.

Large Web corpus has quite a number of application areas, they can help researchers study the phenomenon of language, compiling dictionaries, grammar, teaching reference books, translators can use Web corpus to check the translation of words is accurate, teachers can use network corpus preparation, choose. And practice writing, questions. Some experts have very important application in the classroom, corpus in foreign language teaching. However, the application of corpus and classroom teaching still remains to be cultivated fields. For English learners to overcome the word barrier seems to instead of memorizing without what better way, the emergence of corpus will completely change our mistakes in the understanding of this. Learn a new word just remember its pronunciation, spelling and meaning, but also familiar with the context and the sentence in which it occurs, in order to truly grasp the usage of the word, remember the words firmly. Corpus is such a tool, it can provide a large number of examples, we focus on a word usage, pay attention to the words of the language environment and sentences, for example: describe word it has many meanings, can be translated as: delicate, exquisite, weak and sick, fragile, delicate, delicate, sensitive, precision. But in what circumstances as "delicate", in what situation as "subtle" or "fragile" need the actual example to speak clearly, say. We can find from the various uses of delicate corpus, after careful observation, we will find the definition of the usage and we in the dictionary to the one one. The corpus based study or explaining words can broaden students' horizons, enhance mutual understanding of the word, to enhance the ability of wording and phrasing. Teachers can according to the actual situation of layout of corpus homework, let students use corpus to search for certain words, he concluded. In this way, not only enable students to learn new words, but also cultivate their active learning enthusiasm. If you can master the common phrases and use the collocation of words and phrases[3], it is related to whether the English is authentic or not, and whether it is close to the language of the native speakers. However, any dictionary can relate to the collocation phenomenon is quite limited, it is difficult to meet the needs of English learners to understand the relationship between words and expressions. The collocation of words not only includes the phrase verb, compound noun, preposition phrase, fixed phrase, idiom and so on, but also includes a myriad of habits. Learning English who in understanding and familiar with the 
original, in the translation and sentence making process, anytime, anywhere will encounter a variety of fixed and habitual collocation, in these cases, large corpora most the incomparable superiority. For example, phrasal verbs go about meaning is "engaged in, start" or "to deal with something" "to set about to do, however, to be familiar with and master its usage, meaning in Chinese or English definition alone is not enough. Without contact with a large number of the performance of its relationship with the sentence, it is difficult for any student to grasp the use of this phrase to create a proper sentence. Corpus can help students to fill in the blanks in the process of recognizing phrases and sentence structures, using more examples to deepen the impression of learning, and enhance the learning effect. Following corpus fragment can help students understand "go about" the mix of object and know it contains in the meaning of a transaction, chores or activity.

\section{Discrimination of the system synonyms}

The collocation of words and phrases in large corpora can help us to differentiate and analyse the synonyms, which can play a role in differentiating dictionaries. Let us look at another example, in Advanced English the second book Lesson Five love is a fallacy, in the second sentence of paragraph four consecutive five synonymous with sea, calculating, perspicacious, acute and astute. Although the Senate of the five words distinguishes in the definition and discrimination dictionary also has a more incisive explanation, but due to the lack of examples, teachers will found the explanation to help students understand the difference is very limited, read the students of the Senate often is still difficult to find out. Corpus can help teachers to simplify complex interpretation process. Make the abstract analysis and explanation into a visual contrast, students will feel the difference between these words at a glance. In these five words, calculating and perspicacious in the usage and translation of several other words have a greater difference, can be explained. And the other three words in observing and understanding ability, then both the in the English definition or meaning in Chinese translation are very close, "unusual mental agility or perceptiveness", with in corpus network can make the problem easier. By contrast, it is easy to notice that these three synonyms tend to be paired with nouns, and keen mainly refers to the ability to understand, observe and feel. Acute, in addition to the ability to express a sense of observation and sensitivity, more used to indicate the severity of a state, such as the disease, the problem, etc.. Astute, however, mainly refers to the sharp and keen sense of the people who engage in some kind of profession. Of course, the corpus is not only available for comparison, intuitive language materials, through the use of these corpora, students of language materials observation and judgment ability will be greatly improved.

To master the words and collocations based on, if you want to create the perfect sentence to, we must also familiar with foreign language the basic word order and syntactic structure. In this regard, the network corpus also provides us a way to explore. For example, in the word order, such word order often plagued some students, "such $+\mathrm{a} / \mathrm{an}+$ describe word + noun" and "so + describe word $+\mathrm{A}$ + noun", using the web as corpus we can easily solve the problem, as long as we can get a lot of contains the structure of sentences, each sentence can release a real and vivid language information is such a variety of real language information and repeated the sentence structure to play a strong chemical learning effect in the COBUILD or LDC query box type "such DT JJ NN" or "so JJ DT a|an NN". The In view of this, just summed up the sentence does not completely solve the problem, we need enough real sentences containing the desired patterns, so that students have a deep impression on the sentence structure[4].

Once the network corpus into the classroom, is bound to have an impact on the traditional teaching mode. Traditional foreign language teaching is more easily formed in the environment of lack of teaching materials, after refining the language experts of foreign language information generally by teachers to convey to students, some students mistakenly thought only listen to the teacher carefully in class, you can learn a foreign language. In fact, the ability of initiative and have a great relationship with foreign language information and the effect of foreign language learning. So, there is a sense of modern education schools are trying to provide as much information in foreign language learning for students, make students play the ability of active use of existing 
resources. Network corpus is an extension of the current foreign language teaching resources. The network corpus into the foreign language classroom, students directly contact the corpus, direct contact with the modern real language information, the students will feel like a wide field of vision, swim in the ocean of language. In this learning environment, students need not only some basic concepts of others concluded, they need to find the rules of language personally, personally find language information required for induction. Therefore, teachers need to update the traditional teaching mode, to guide students to make full use of resources on the corpus, to mobilize students' initiative to discover and understand the rules of language.

As a language learning tool, let the network corpus into class should be without rebuke. But how to manage such a huge amount of information tools to effectively utilize network corpus resources for classroom teaching service is the hope that teachers in teaching the application of corpus to face the problems. In the network classroom and other hardware facilities complete, the key to solve the problem is using the internet corpus ability has guiding teacher and a matching teaching plan. Specifically, teachers' guidance content should include: enter the selected corpus and query methods, select the useful information. To consider the implementation of network teaching program content corpus:

1) in determining to solve problems and the use of teaching materials in the corpus before class solution to the problem.

2) there is a shortcut on the desktop to the spare corpus and dictionary tools.

3 ) to guide students to master the basic method of using corpus, so that they gradually adapt to the fast query and can participate in classroom activities.

4) design using a corpus of classroom activities to guide students to find the answer to the problem independently and participate in class discussion.

5) corpus layout homework must, so that students in the class in the process of review and preview the purpose of using corpus resources.

The core of the implementation of network corpus teaching scheme is to give students in the corpus to explore and discover the language rules and discuss opportunities in organized classroom[5].

\section{Conclusion}

The use value of the network corpus is obvious. To try to use the network corpus can fundamentally change our understanding of the current foreign language teaching resources. For schools with a remote area, lack of foreign language teaching materials, network corpus resources are more valuable. In time to explore and use the network corpus resources can quickly and effectively enhance the ability to support foreign language teaching and improve the quality of foreign language teaching. Direct online using the BNC and COBUILD and LDC corpus with its rich corpus, fast and convenient way of inquiry can meet the needs of teachers and students to know all kinds of linguistic phenomena, solve the problems of teaching, they will become indispensable to the foreign language classroom learning tool. In order to promote the network corpus teaching, we need to have a group of enthusiastic in traditional foreign language teaching pattern reform of first-line teaching staff, a bold attempt to corpus network, to explore the implementation of network teaching method of the corpus, through extensive exchanges use corpus of teaching experience, enable the network resources for China's modern foreign language classroom teaching service.

\section{References}

[1] S.I. Hayakawa, 1968. Use the Right Word, Modern Guide to Synonyms and Related Words[M]. Hong Kong: Readers Digest Association.

[2] Stevens, Vance. 1995. Concordancing with language learners: Why? When? What? [J] CAELL Journal Vol 6, No. 2 pp. 2-10. 
[3] Cobb, T. 1997. Is there any measurable learning from hands-on concordancing? [J] System, 25, 301-315.

[4] oraltests [j]. language testing, 1994, (11): 99-123.

[5] Cai Jigang. The validity, reliability and operability of the four and six computer oral test in College English [j], 2005, (4):66-75. 